Please quote as: Schöbel, S.; Janson, A.; Ernst, S. -J. \& Leimeister, J. M. (2017): How to Gamify a Mobile Learning Application - A Modularization Approach. In: International Conference on Information Systems (ICIS). Seoul, South Korea. 


\title{
How to Gamify a Mobile Learning Application - A Modularization Approach
}

\author{
Short Paper
}

\author{
Sofia Schöbel \\ University of Kassel \\ Information Systems \\ Pfannkuchstraße 1, 24121 Kassel, \\ Germany \\ sofia.schoebel@uni-kassel.de \\ Sissy-Josefina Ernst \\ University of Kassel \\ Information Systems \\ Pfannkuchstraße 1, 24121 Kassel, \\ Germany \\ sissy.ernst@uni-kassel.de
}

\author{
Andreas Janson \\ University of Kassel \\ Information Systems \\ Pfannkuchstraße 1, 24121 Kassel, \\ Germany \\ andreas.janson@uni-kassel.de
}

\author{
Jan Marco Leimeister \\ University of Kassel / University of St. \\ Gallen \\ Information Systems / Institute of \\ Information Management \\ Pfannkuchstraße 1, 34121 Kassel, \\ Germany / Müller-Friedberg-Strasse 8, \\ 9000 St. Gallen, Switzerland \\ leimeister@uni-kassel.de / \\ janmarco.leimeister@unisg.ch
}

\begin{abstract}
Countless possibilities of usage make it more and more difficult to engage and motivate users in a regular use of mobile learning applications. However, users must be convinced to complete and explore every given option within the application. Considering this, gamification seems to be a promising approach to engage and motivate users. Gamification refers to the use of game-like elements in a non-entertainment-based context. Regarding previous research, most game design elements are randomly selected and combined. This is why we use modularization to systematically select and combine game design elements. Following the design science approach and the cognitive evaluation theory, we aim to define a new way of gamifying a mobile learning application. We, therefore, present an approach for the combination of game design elements. Contributions will be given by providing guidance in how to systematically select and combine game design elements.
\end{abstract}

Keywords: Gamification, Motivation, Mobile Learning Application, Modularization

\section{Introduction}

The increasing usage of wireless technology, such as smartphone usage, changes today's individual communication, (a person's) information seeking behavior, and the lifestyle of individuals in particular (Kim et al. 2013). The interaction with mobile devices and their use for learning purposes extend the traditional learning paradigm into a new area of mobile learning (Su and Cheng 2013). Referring to this, learning is no longer a matter of a specific time of occurrence or a particular location (Bartel and Hagel 
2014). Research suggests that mobile devices enable individuals to experience a more interactive learning thereby improving engagement, learning, and course retention (Joosten and Stoerger 2011). Furthermore, using new technologies such as mobile devices can enhance motivation, deliver information when needed, encourage to solve problems, and satisfy curiosity (Sharples et al. 2002). Motivation is an important aspect of learning and quite necessary to engage users in learning activities (Cheong et al. 2013; Huang et al. 2009). Accordingly, user engagement becomes more important. Engagement means that users want to complete an activity and explore every given option (Cheong et al. 2013). However, user engagement is difficult to reach as it is not just about making the experience user-friendly. The application needs to convince users that what they are supposed to do is usable, useful and desirable (Law et al. 2011). Games are particularly successful when it comes to individual engagement in daily life. For that reason, games are the preferred mean to motivate users of information systems (IS) to a continuous use of the system (Davis and Singh 2015). The described approach is called gamification and refers to the integration of so-called game design elements in a non-entertainment-based context (Deterding et al. 2011).

Referring to previous research studies, most gamification approaches are designed without knowing which game design elements should be selected and combined and how (Fleming 2014, de-Marcos 2015). Furthermore, game design elements are often selected and combined randomly, without considering situational or contextual aspects or the needs of users and thus, they are not consistent for quite a few cases (Hanus and Fox 2015). This can be observed in different results of gamification approaches. Changing an element can influence the effects on motivation and usage. Seixas et al. (2016) and Hamari et al. (2014), for example, combined the elements points, badges, level, and goals. Both research studies could prove positive results. However, Hanus and Fox (2015) used the same elements, but instead of using levels and goals, they used a competitive leaderboard. Contrary to the results of Seixas et al. (2016) and Hamari et al. (2013), the results were negative. Due to this, further research is necessary to define a method for the systematic design and combination of game design elements (Fogel 2015). Even more, future research has to consider how gamification should be systematically adapted to make it more engaging for users (Cheong et al. 2013; Su and Cheng 2013). Since most gamification approaches forego a theoretical embedding for the selection of game design elements, our study focuses on the cognitive evaluation theory (CET Ryan and Deci 2000). The goal of our research study is to introduce a new possibility of selecting and combining game design elements and provide guidance under the consideration of contextual aspects by relying on a modularization approach (Janson et al. 2014a). Furthermore, due to the randomized selection and combination of game design elements in previous studies, modularization can be one approach for a repeatable and systematical selection of game design elements. To achieve our goal, we follow the design science approach (Hevner et al. 2004; Peffers et al. 2007) and focus on gamifying a mobile learning application to demonstrate the utility of the approach. By using the design science approach, we will be able to design and adapt game design elements to an already existing and non-gamified mobile learning application. Our research provides several theoretical and practical contributions. First, we are able to obtain a better understanding of how game design elements can be combined. This will enrich gamification theory, as we provide a new possibility of selecting and combining game design elements that enables researchers to consider situational as well as contextual aspects for their gamification approaches. Second, by using CET, we can derive implications about the role and the meaning of an individual's feeling of autonomy and competence in relation to specific game design element combinations. Thus, we are able to provide practical contributions to system designers because the proposed approach guides the selection and combination of game design elements under consideration of contextual aspects.

\section{Theoretical Background}

\section{Gamification}

The term gamification originated in the digital media industry (Deterding et al. 2011). In their work, Schlagenhaufer and Amberg (2015) point out that the first gamified system was introduced by Bunchball. After that, companies started to use gamification for marketing purposes before expanding to other areas. Two of the most widespread definitions are outlined by Deterding et al. (2011) and Hamari et al. (2014). Deterding et al. (2011) define gamification as an informal umbrella term for the use of video game elements in non-gaming systems with the aim to improve user experience and user engagement. Hamari et al. (2014) defined the term as a process of enhancing services with (motivational) affordances in order to invoke gameful experiences and further behavioral outcomes. Additionally, Hamari et al. take their definition 
further and elaborate on it by including certain characteristics. They suggest that gamification contains three parts, namely the implemented motivational affordances, the resulting psychological outcomes, and the further behavioral outcomes. Summarizing the above-mentioned definitions, gamification can be seen as "the use and combination of game design elements in non-game contexts" (Deterding et al., 2011), which ideally cause a psychological outcome (Hamari et al., 2014) leading to motivational incentives. The so-called game design elements are one important issue for our research. Hunicke et al (2004), were the first who divided game design elements into certain groups by using a so-called MDA framework, which includes game mechanics, game dynamics, and game aesthetics. Mechanics can be defined as the functioning components of the game that allow the designer ultimate control over the levels of the game, thereby also meaning that the designer is able to guide the actions of an user (Zichermann and Cunningham 2011). Dynamics are described as the user's interactions with those mechanics. They determine what each user is doing in response to the mechanics of the system. Aesthetics are characterized as emotional triggers felt by the user during the interaction.

To get a first impression of the game design elements that have successfully been used in previous research studies, a systematic database search was applied including the following databases: ACM Digital Library, AIS Electronic Library (AISeL), EBSCOHost, Emerald Insight, Institute of Electrical and Electronic Engineers (IEEE), Xplore Digital Library and JSTOR (Vom Brocke et al. 2015; Webster and Watson 2002). By using the key words "gamification", "game design elements", "game elements", "gamification elements," and "learning", we were able to identify 56 research papers. Overall, we can say, that gamifying a mobile learning application is handled in the same way as integrating game design elements in a learning management system (Filsecker and Hickey 2014; Perry 2015). In both cases, the same game design elements are being used and integrated. Referring to our study, we can use our mobile learning application as an application example. Overall, game design elements are oftentimes randomly selected without the consideration of contextual or situational aspects. At this point, we can use modularization for systematically selecting and combining game design elements. Focusing on the game design elements that are mostly and successfully used in previous studies, our literature review indicates that goals are used in 48 of our 56 studies. Thirty-eight studies used a point system, 33 studies used badges, 32 used a leaderboard, 32 used feedback, 28 used a level, 19 used a virtual character, and finally 14 made use of time pressure. All of these elements are considered mechanics; they are used for gamifying an information system or a mobile application. On the other hand, most studies used collaboration (21 studies) or competition (35 studies) for embedding their gamification concept. Embedding means to make a decision for which activities individuals can earn badges or points. In a competitive setting, users receive points or badges for having better results than other users. 16 studies also used bonuses, such as additional points, as game design elements (de-Marcos et al. 2015). To specify the meaning of the implemented gamification concept, most studies used meaning (41 studies) and progressive disclosure (15 studies). Based on the results of our literature review, we decided to focus on the most often used elements. These elements can be seen in Figure 1.

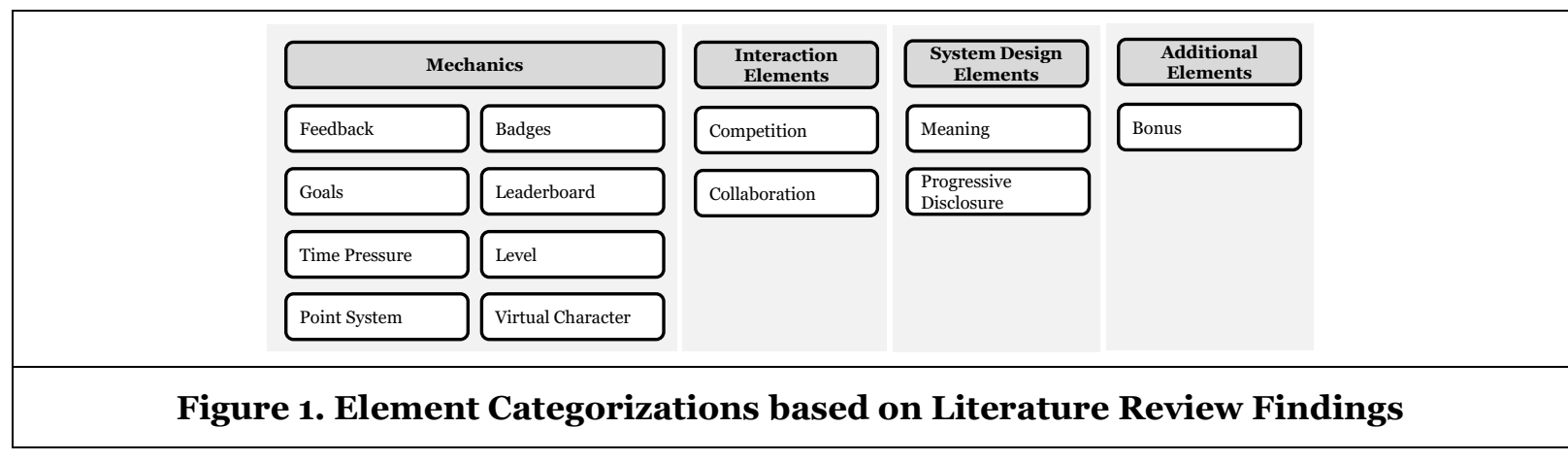

Each game design element has a specific function and meaning. Feedback is given to reflect the progress or failure of an individual user (Burgers et al. 2015). Goals can be reached by completing a task or activity (Domínguez et al. 2013). When integrating time pressure, users have to complete a task as fast as possible; they work under time pressure (Burgers et al. 2015). A point is a reward for successfully performing a task. Mostly, they are part of an overall point score (Attali and Areli-Attali 2015). By using badges, users are rewarded in form of a visual icon (Hamari 2013). A leaderboard offers the opportunity to compare own results with those of others (Hanus and Fox 2015). Levels indicate the progress of a user and his overall 
performance within the game (Melero et al. 2015). A virtual character accompanies a user throughout the use of a system; he is the representation of the user (Christy and Fox 2014). Finally, as mentioned before, elements for the overall system design are meaning and progressive disclosure. When using the element of meaning, a user should be able to realize why a game is meaningful to him, e.g. by considering the organizational context (Palomo-Duarte et al. 2014). Progressive disclosure means to increase skills of knowledge and challenge. Therefore, the challenges individually match the users' skills(Domínguez et al. 2013).

\section{Cognitive Evaluation Theory and Mobile Learning}

In order to find an explanation for the phenomenon that individuals like to play games, many studies refer to motivational theories as they consider intrinsic and extrinsic motivation of individuals and psychological needs (Aparicio et al. 2012). Self-determination theory (SDT) addresses intrinsic as well as extrinsic motivation (Ryan and Deci 2000). Playing computer games does not always evoke extra rewards. Indeed, computer players play games to be involved and because they enjoy participation, too. That means that people like to play these games because they are intrinsically motivated (Bartle 2004). Within our research, we focus on one of the SDT mini theories: the CET, which is concerned with contextual factors that support intrinsic motivation (Ryan and Deci 2000). Intrinsic motivation is encouraged by a person's sense of autonomy and competence whereas factors that decrease perceived autonomy and competence undermine intrinsic motivation (Ryan et al. 2006). When an individual fulfills a task or activity out of interest or personal values, we indicate that as autonomy as refers to the sense of will of a person when performing a task. (Ryan et al. 2006). Hence, providing choices and using rewards as informational feedback and noncontrolling actions enhances autonomy. Playing games is considered rather voluntary which explains high motivation effects. Therefore, Ryan and Rigby (2006) expect autonomy to be enhanced by game designs that provide flexibility within the chosen game design elements, such as the choice over tasks and goals. Concerning CET, competence is the second psychological need (Ryan and Deci 2000). Competence describes the need of individuals to take part in challenges in order to feel more capable and efficient. A strong competence points out that individuals want to compare their achievements with those of others because they believe to be superior. Furthermore, competence refers to self-presentation which means that an individual likes to impress other individuals with a positive self-presentation (Mummendey 1990).

Within our research study, we will analyze a mobile learning application. Mobile learning enables people to gather information on the move as access to information and knowledge, to handhelds, and to portable devices is always possible (Pieri and Diamantini 2009). Learners have the possibility to learn anywhere and at any time. Besides these two aspects which are emphasized in most research studies giving a definition for mobile learning (Denk et al. 2007), other aspects like real-time interaction with learning material, lecturers, and peers play a significant role (Koole 2009). Already when applying factual knowledge is required, e.g. when setting up a computer or car. Mobile learning can lead to improved outcomes for learners, in terms of training success compared to traditional learning scenarios, as it allows for the provision of immediate and direct feedback (Gómez et al. 2014) as well as contextual acquisition of skills (Walker 2006). Against this backdrop, the mobile learning application presented in this research paper is built with the aim to allow for a contextual acquisition of skills by interacting with QR-codes attached to a car (Ernst et al. 2016). The mobile learning application is used in the context of the vocational training of motor mechanics in China. Since we want to keep our target group motivated not only in voluntarily using the mobile learning application but also in addition to regular training sessions, we follow the gamification approach. For a systematic combination of the integrated game design elements, we use a modularization approach to identify element combinations.

\section{Research Method}

\section{Modularization of Game Design Elements}

As we refer to design science, our objectives for a solution of the above described problem (Peffers et al. 2007) is the concept of modularization under consideration of CET. To keep users motivated in using the mobile learning application regularly, we want to integrate game design elements into our developed application. We use modularization principles to identify game design element combinations regarding CET. Modularization offers the possibility of mass customized and individual offerings and it allows an 
individual configuration of possible services such as adapting game design elements to motivational structures of users. Modularity is based on the principles of cohesion and loose coupling (Janson et al. 2017a). A high cohesion for instance, is necessary for well-specified modules that can easily be reused and combined with other modules. As the motivational effects of games are always connected to psychological needs of individuals, we used the CET in combination with the process levels of our mobile learning application. By using modularization, we were able to create game design element combinations for each process level. The created game design element combinations can easily be transferred to other process steps because game design elements fulfil the principles of loose coupling; they can be replaced by other elements that have the same motivating effect. Furthermore, due to the characteristics of modularization, such as loose coupling and cohesion and besides focusing on mobile applications, our approach can be transferred to other fields of applications.

\section{Identification of Game Design Element Combinations}

According to the design science approach (Peffers et al. 2007), we will describe the way we are going to design our game design element combinations for our mobile learning application in the following. Our artifact is a methodological framework for the combination of game design elements and with considering motivation theory and modularization. Hence, our modularization approach includes CET and the learning process steps of our application (Janson et al. 2017b; Söllner et al. 2017). Our mobile learning application was constructed for vocational students of the automotive area. The construction of the basic mobile learning application as well as an evaluation are presented in Ernst et al. (2016).

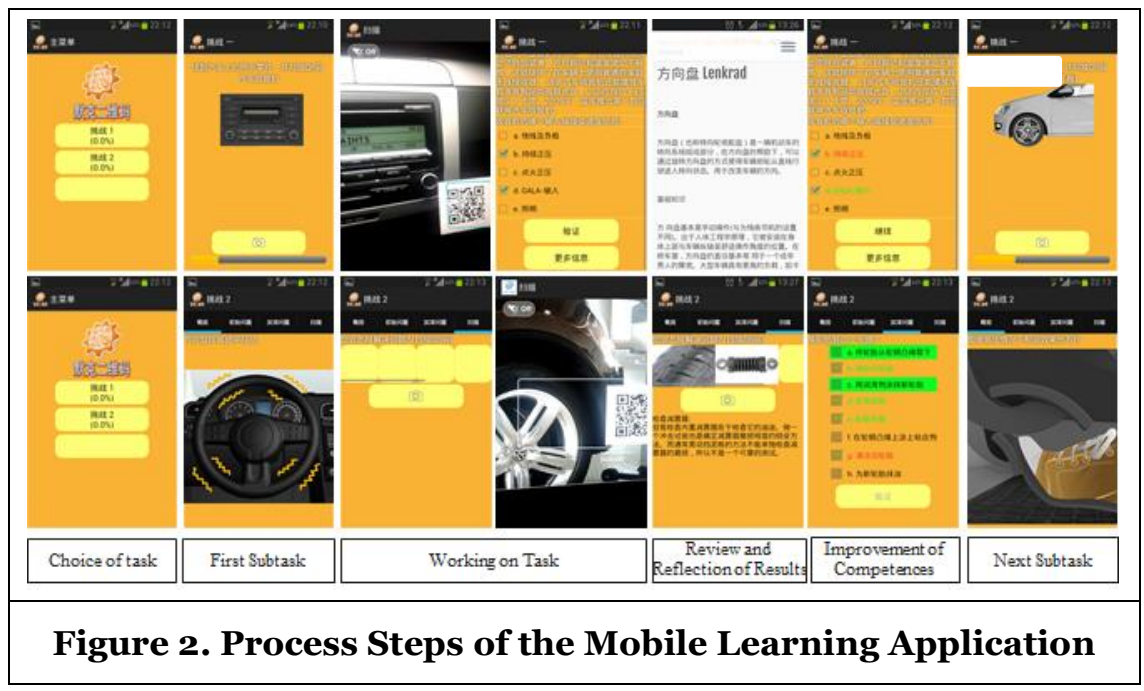

The different process steps of our mobile learning application can be seen in Figure 2. While the upper part represents module 1 , which is considered with acquiring declarative knowledge, the lower part represents module 2, which is considered with acquiring procedural and skill-based knowledge. When starting the mobile learning application, a user can choose between different tasks of learning modules (subtasks). Following Gupta and Bostrom (2013) the application offers two types of tasks, each connected to diverse types of knowledge: the mobile learning application facilitates declarative knowledge by compromising fundamentals but it also facilitates procedural and skill-based knowledge by displaying damage descriptions and asking the user to develop a strategy to detect the cause of damage. While working on a task, a user can see a short task description as well as his progress. Referring to this, a possible task could be to find specific parts of a car such as the wheel or a battery as in scavenger hunts (Ceipidor et al. 2009). Regarding tasks to train procedural knowledge, a problem is presented to the students, for instance: "The street is not illuminated enough. What do you do to fix this problem?". Users are now supposed to select $\mathrm{QR}$ codes on the parts of a car in the right order. After they selected a QR Code, an explanation about the different parts of the car are presented in the mobile learning application. Then, a review and reflection of the results is presented. For improving the individual user's competence, we included knowledge tests for learning modules within our mobile learning application. While knowledge tests are used for training a user's procedural knowledge, searching for the right QR codes focuses on training their skill-based 
knowledge. After finishing a task or knowledge test, the user can see which tasks he has already completed and which ones are still to be answered. To improve individual competencies of users, all tasks and knowledge tests can be repeated. Furthermore, possible tasks are visualized which might help to complete individual competencies. In the last step, the user can select the next subtask he or she likes to work on. The general development of the mobile learning application with all different process steps has already been evaluated (Ernst et al. 2016). The goal of our research study is to select and combine game design elements under consideration of contextual aspects by considering a modularization approach. Referring to modularization, the different process steps can be seen as modules. Independent from using QR codes in the application, each process step can be used in any learning management system or application. More precisely, nearly every learning management system uses knowledge tests as well as studying material (Faghihi et al. 2014; Filsecker and Hickey 2014; Perry 2015). By using modularization, we intend to decide which game design element combination should be used in which process step to address the users' feeling of autonomy and competence.

In a two-staged process, two independent researchers familiar with our mobile learning application and gamification coded the game design elements following CET ( $1=$ use of an element within, $0=$ element should not be used). Before the coding procedure, both coders received detailed definitions of the game design element in which their meaning as well as characteristics were presented. Furthermore, to understand CET, they received several documents with explanations about the theory as well as research papers. Finally, both coders received information about the mobile learning applications and the functions. Before starting with the coding procedure both coders had the opportunity to ask questions about CET or different game design elements. We provided documents with information about the coding procedure. The first coder coded the game design elements for autonomy and competence. In a subsequent step, the second coder checked the results and edited the document. By computing the Pearson correlation between the two coders, a statistically significant inter-rater reliability of $0.888(\mathrm{p}<.001)$ for autonomy and 0.838 ( $\mathrm{p}<.001)$ for competence was obtained, which is, in accordance with Tinsley and Weiss (1975), within the suggested range of .80 to .90 . In a subsequent discussion, the two coders resolved any differences on their own until both agreed on a game design element selection that was finally used for the following results. The first coding result is the game design element combination under consideration for autonomy. Individuals have the feeling of autonomy, when they fulfill a task out of interest or because of personal values; it refers to the sense of will of an individual when performing a task. Hence, the coders had to decide in which of the process steps the individuals' autonomy could be addressed. If they decided that one of the process steps is usable for addressing their autonomy. Based on the description and characteristics of the different game design elements, the coders now had to decide which element could fit to the particular process steps. The coders proceeded in the same way during the coding procedure for competence. First, we will describe the coding results of the category of autonomy which can be seen in Table 1 .

\begin{tabular}{|l|l|l|l|l|l|l|l|l||l|l||l||}
\hline \multicolumn{7}{|c|}{ Table 1. Modularization of Game Design Elements for Autonomy } \\
\multicolumn{1}{|c|}{ Gamification } \\
Elements
\end{tabular}

According to the results, feedback can be used in the process step of review and reflection of the results as well as for the competence improvement. Different goals for each learning module can be included in almost 
every process step. To address the users' feeling of autonomy, and hence, to allow flexibility, a user should be able to select between different goals whenever he chooses a task to support individual learning. According to time pressure, it cannot be used in one of the process steps. This seems to be logical, since time pressure does not allow for a flexible learning, which is however necessary for addressing autonomy. The mechanics point system, badges, and the leaderboard can be used only for the step of individual competence improvement. Additionally, to provide feedback and to address user's autonomy, levels can be integrated into the step of review and reflection of results as well as for the competence improvement. Overall, a virtual character can be used for the representation of a user. Avatars can be individually designed by a user, which by the way also addresses his feeling of autonomy (Seo et al. 2017). Referring to our coders' discussion, autonomy can be integrated during the step of working on a task and competence improvement. More precisely, a user can work within a group by integrating collaboration. He is then able to ask for help, offer help to others, or lead others to find answers. Competition can be integrated during the competence improvement, by allowing the learner to compare his or her results with the results of others. For addressing autonomy by using progressive disclosure, every process step should refer to the individual skill of a user. Additionally, besides the step of the next task and subtask, the meaningfulness of each step should be explained to the user. Referring to autonomy, a bonus for scanning all codes correctly can be integrated as an additional reward during the competence improvement. Referring to competence, individuals want to take part in challenges to feel more competent and efficient (Ryan and Deci 2000). Hence, a strong competence points out that individuals want to compare their results in learning with those of others because they think that they are superior. The results of the coding for mechanics within the area of competence can be seen in Table 2.

Table 2. Modularization of Game Design Elements for Competence

\begin{tabular}{|c|c|c|c|c|c|c|c|c|c|c|c|c|c|}
\hline $\begin{array}{r}\text { Gamification- } \\
\text { Elements }\end{array}$ & 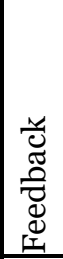 & 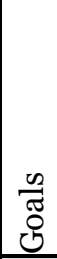 & 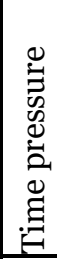 & 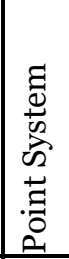 & 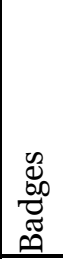 & 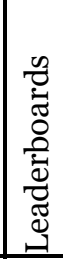 & 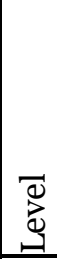 & 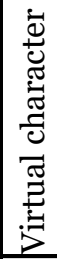 & 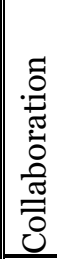 & 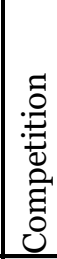 & 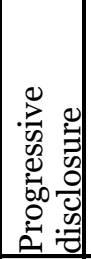 & $\stackrel{\infty}{\Xi}$ & 告 \\
\hline Choice of Task/Subtask & 0 & 1 & 0 & $\mathrm{O}$ & 0 & 0 & $\mathrm{O}$ & 1 & 0 & 1 & 1 & 1 & 0 \\
\hline Working on Task & 0 & 0 & 1 & 0 & 0 & 0 & 0 & 0 & 1 & 1 & 1 & 1 & 0 \\
\hline Review/Reflection of Results & 1 & 0 & 0 & 0 & 0 & 0 & 1 & 1 & 1 & 1 & 0 & 1 & 0 \\
\hline Competence Improvement & 1 & 1 & 1 & 1 & 1 & 1 & $\mathrm{O}$ & 1 & 0 & 1 & 0 & 1 & 1 \\
\hline Next Task/Subtask & 0 & 1 & 0 & 0 & 0 & 0 & 0 & 1 & 0 & 1 & 0 & $\mathrm{O}$ & 0 \\
\hline
\end{tabular}

Competitive adapted feedback can be given to learners in the process steps of review and reflection of the results as well as during the competence improvement. When choosing a task, a user can select between general goals and competence-related goals. In the step of the competence improvement, a user is able to see which of the competitive goals he has already fulfilled. Unlike the coding results for autonomy, time pressure seems to be very useful for challenging users and for addressing their feeling of competence. Time pressure can be used while working on a task and within the competence improvement. Besides the level, all other mechanics have the same coding results. Therefore, a level for addressing the competence of users should merely be integrated into the process step of review and reflection of the results. Referring to the interaction elements, our coder's competition is necessary for each of the process steps. Additionally, group results can be compared by integrating and combining collaboration and competence. Therefore, users can work on a task within a group that has the intention of getting better results than other groups. Allowance for the comparison of the group's own results with others can be integrated in the step of the review and reflection of results. Referring to system design elements, progressive disclosure for addressing competence is only useful before and during task performance. Again, the meaning related to the competence is important in every process step besides the next step and subtask. A bonus which addresses the competence of a user seems to be useful only in the process step of the competence improvement. Unlike a bonus for addressing autonomy, competence-related bonuses should be given for successfully finishing challenges 
(Burke and Hiltbrand 2011). Overall, for addressing competence, competition and time pressure seem to be most important. Specific competitive goals or earing points for performing better than others should be integrated in our mobile learning application. Figure 4 represents the results of our coding procedure. Generally, we can build game design element combinations for each process level under the consideration of CET. Intrinsic motivation is encouraged by an individual's sense of autonomy and competence in equal measures (Ryan and Deci 2000). By combining the coding results of autonomy and competence, we could identify game design combinations for each of the process steps. The combinations can be seen in Figure 3.

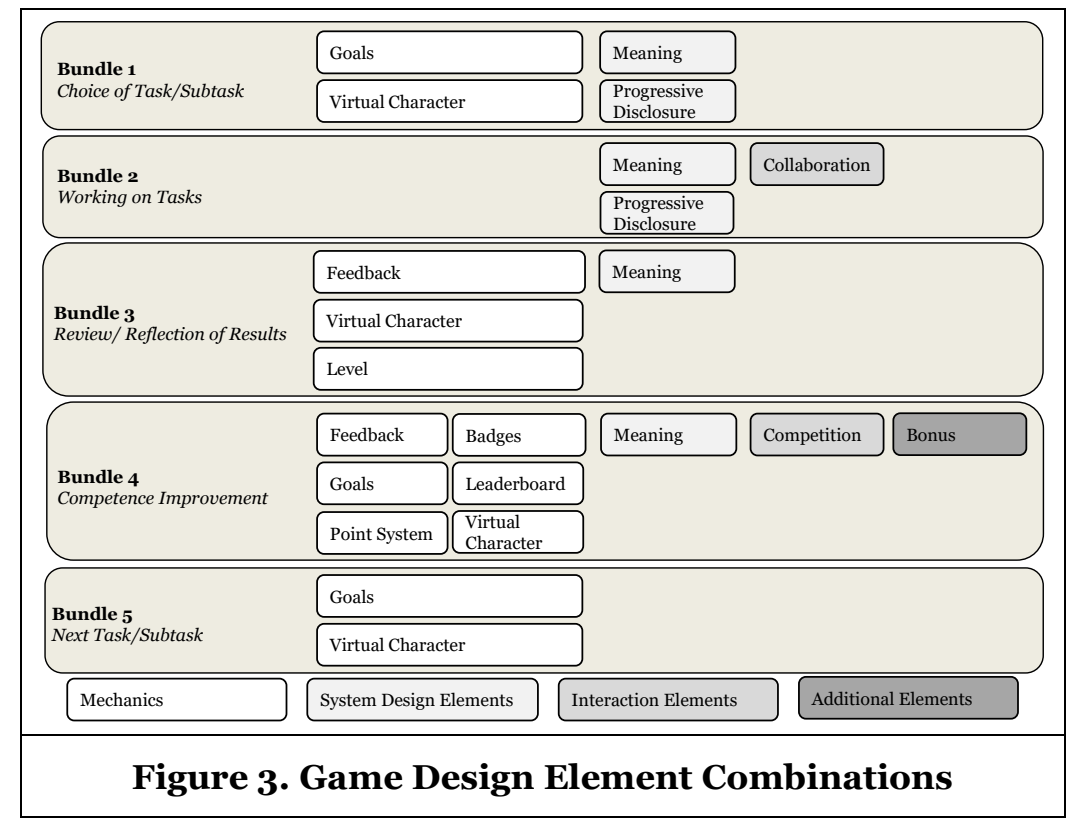

Overall, mechanics such as points or badges are basically integrated in the process step of competence improvement. The step of competence improvement is the most extensive one and it is based on the learning material users study while working on a task and the review and reflection on results. By integrating knowledge tests users can examine whether they understood the previous learning contents or not. A knowledge test consists of several different tasks. Points, for example, have to be collected because they are part of an overall point score (Attali and Areli-Attali 2015). A leaderboard can be used in combination with points (Hanus and Fox 2015). For addressing autonomy and competence, we will adapt the given feedback, points, badges, and goals. Integrating interaction elements such as competition or collaboration only seems to be useful when users are working on a task. During the process of scanning QRCodes all users are in front of a car and can talk to each other. Hence, they have the possibility of working together (Jurado et al. 2014). Competition on the other hand can be integrated by using a leaderboard (Thiebes et al. 2014). Besides the step of 'next task', our results indicate that meaning is important for every process step, no matter if it is for addressing competence or autonomy. Hence, we will include an explanation about the meaningfulness of our mobile learning application in each process step (Janson and Thiel de Gafenco 2015; Palomo-Duarte et al. 2014). Finally, a bonus can only be integrated in the step of competence improvement. Since a bonus is an additional reward, the presence of other rewards is necessary (Thiebes et al. 2014). According to our results, bonuses can be given for rewarding both autonomy and competence-related behavior. For example, the bundle for the process step choice task will consist of goals, a virtual character, meaning and progressive disclosure. We will use progressive disclosure when presenting tasks of various difficulty stages. Recommendations on the task selection will be given. After a user has selected a task, different goals will be presented. We will integrate goals that address competence as well as autonomy. Furthermore, for allowing a higher flexibility, users can choose between different goals they like to achieve by working on the presented task. A virtual character can be designed by each user, to give them the feeling of autonomy. It is the virtual representation of his own seen whenever a user interacts with other users in a leaderboard or a group task. 


\section{Experimental Evaluation}

Regarding the design science approach, our next step is the demonstration and evaluation of the identified game design element combinations (Peffers et al. 2007). We want to evaluate our gamified version of the mobile learning application with vocational students of the automotive area as well as an adapted version with learners in the processing industry. The learners we are going to involve are between 15 and 22 years old and they are in the beginning of their training. Hence, they mainly possess basic knowledge and the application will be useful in term of increasing their knowledge. For evaluating our developed game design element combinations, we will conduct a between-subjects design experiment. The control group will work with a non-gamified version of the mobile application. In addition to that, we will have two treatment groups. The first treatment group will use a mobile learning application with our identified game design element combinations. The second treatment group will also receive a gamified version but in this version the game design elements are being picked and added to different process steps by an experienced IS designer. Each student will be randomly assigned to one of the three groups. In a first step, they will use the mobile learning application during their lectures. Afterwards, we are going to give a survey to each of the students. We will use a t-Test to evaluate whether there is a significant improvement in user engagement, in the motivation to use the mobile learning application, and in learning outcomes. Following Gupta and Bostrom (2013), we will measure cognitive knowledge acquisition as well as meta-cognitive and affective learning outcomes to gain insights regarding the learning outcomes of students (Janson et al. 2014b). Students' cognitive knowledge will be assessed by the results of various tasks given to them plus their knowledge test results., Finally, to measure affective learning outcomes, we will evaluate the student's level of satisfaction (Chin et al. 1997). For measuring effects on motivation, we will use scales of CET to identify how users are getting motivated (Chen et al. 2014; Deci et al. 1994; McAuley et al. 1989). Additionally, we will use scales to measure the intensity of intrinsic and extrinsic motivation as well as scales for engagement and motivation in use (Pintrich 1991; Ryan and Deci 2000; Vos et al. 2011).

\section{Limitations, Next Steps and Expected Contributions}

The goal of our research study was to introduce a new possibility of selecting and combining game design elements. By using CET in combination with a modularization approach, we describe one possibility for systematically identifying and combining game design element combinations. This short paper is not without limitations. However, our limitations provide many avenues for future research. Our study focuses on vocational students in China in two domains. Due to cultural differences, the results may vary in contrast to other samples from the US or Europe (Janson et al. 2016). Hence, future research studies should be conducted with other subject groups such as university students. Our modularization approach could then be used to gamify other learning management systems as well. Referring to this, we focused on identifying game design element combinations only for a mobile learning application. Hence, additional analyses are necessary to find out whether our approach is transferable to other learning management or IS. This research has several theoretical as well as practical contributions. We will enrich gamification theory by developing an approach for the systematic combination and integration of game design element combinations. Such a systematic approach can be useful to address situational as well as contextual aspects during the development process of a gamified application. Additionally, and according to CET, we provide implications about how to address an individual's autonomy as well as competence by game design element combinations. As a practical contribution, we provide guidance to lecturers and IS designers on how to select and combine game design elements under the consideration of motivational aspects of users.

\section{Acknowledgements}

This paper presents research that was conducted in context of the projects "StaySmart" (funding number: 02L12A170, managed by the Project Management Agency Karlsruhe - PTKA) and "KoLeArn" (funding number: 01BE17008A, managed by the DLR Project Management Agency - PT-DLR), both funded by the German Federal Ministry of Education and Research (BMBF). The responsibility for the content of this publication remains solely with the authors. 


\section{References}

Aparicio, A. F., Gutiérres Vela, F. L., Gonzáles Sánchez, J. L., and Isla Montes, J. L. 2012. "Analysis and application of gamification," Proceedings of the 13th International Conference on Interacción PersonaOrdenador.

Attali, Y., and Areli-Attali, M. 2015. "Gamification in assessment: Do points affect test performance," Computers \& Education (83), pp. 57-63.

Bartel, A., and Hagel, G. (eds.). 2014. Engaging students with a mobile game-based learning system in university education, IEEE.

Bartle, R. 2004. Designing virtual worlds, CA: New Riders: Berkeley.

Burgers, C., Eden, A., van Engelenburg, M. D., and Buningh, S. 2015. "How feedback boosts motivation in play in a brain-training game," Computers in Human Behavior (48), pp. 94-103.

Burke, M., and Hiltbrand, T. 2011. "How Gamification Will Change Business Intelligence," Business Intelligence Journal (16:2).

Ceipidor, U. B., Medaglia, C. M., Perrone, A., Marsico, M. de, and Di Romano, G. (eds.). 2009. A museum mobile game for children using QR-codes, ACM.

Chen, B., van Assche, J., Vansteenkiste, M., Soenes, B., and Beyers, W. 2014. "Does Psychological Need Satisfaction Matter When Environmental or Financial Safety are at Risk?" Journal of Happiness Studies (16:3), pp. 745-766.

Cheong, C., Cheong, F., and Filippou, J. 2013. "Quick Quiz: A Gamified Approach for Enhancing Learning," Pacific Asia Conference on Information Systems.

Chin, W. W., Gopal, A., and Salisbury, W. D. 1997. "Advancing the theory of adaptive structuration: The development of a scale to measure faithfulness of appropriation," Information Systems Research (8:4), pp. $342-367$.

Christy, K. R., and Fox, J. 2014. "Leaderboards in a virtual classroom: A test of stereotype threat and social comparison explanations for women's math performance," Computers \& Education (78), pp. 66-77.

da Rocha Seixas, L., Gomes, A. S., and de Melo Filho, Ivanildo José. 2016. "Effectiveness of gamification in the engagement of students," Computers in Human Behavior (58), pp. 48-63.

Davis, K., and Singh, S. 2015. "Digital badges in afterschool learning: Documenting the perspectives and experiences of students and educators," Computers \& Education (88), pp. 72-83.

Deci, E. L., Haleh, E., Brian, P. C., and Leone, D. R. 1994. "Facilitating internalization: the selfdetermination theory perspective," Journal of personality (62), pp. 119-142.

de-Marcos, L., Garcia-Lopez, E., and Garcia-Cabot, A. 2015. "On the Effectiveness of Game-like and Social Approaches in Learning: Comparing Educational Gaming, Gamification \& Social Networking," Computers \& Education, pp. 1-35.

Denk, M., Weber, M., and Belfin, R. 2007. "Mobile learning-challenges and potentials," International Journal of Mobile Learning and Organisation (1:2), pp. 122-139.

Deterding, S., Dixon, D., Khaled, R., and Nacke, L. 2011. "From Game Design Elements to Gamefulness: Defining "Gamification"," Proceedings of the 15th International Academic MindTrek Conference Envisioning Future Media Environments.

Domínguez, A., Saenz-de-Navarrete, J., de-Marcos, L., Fernández-Sanz, L., Páges, C., and MartínezHerráiz, J.-J. 2013. "Gamifying learning experiences: Practical implications and outcomes," Computers \& Education (63), pp. 380-392.

Ernst, S.-J., Janson, A., Söllner, M., and Leimeister, J. M. 2016. "It's about Understanding Each Other's Culture - Improving the Outcomes of Mobile Learning by Avoiding Culture Conflicts," International Conference on Information Systems (ICIS), Dublin, Ireland.

Faghihi, U., Brautigam, A., Jorgenson, K., Martin, D., Brown, A., Measures, E., and Maldonado-Bouchard, S. 2014. "How Gamification Applies for Educational Purpose Specially with College Algebra," Procedia Computer Science (41), pp. 182-187.

Filsecker, M., and Hickey, D. T. 2014. "A multilevel analysis of the effects of external rewards on elementary students' motivation, engagement and learning in an educational game," Computers \& Education (75), pp. 136-148.

Fogel, G. 2015. Will 80\% of gamification projects fail? Giving credit to Gartner's 2012 gamification forecast. http://www.gameffective.com/gamification-basics/will-80-of-gamification-projects-fail/. Accessed 30 October 2015. 
Gómez, S., Zervas, P., Sampson, D. G., and Fabregat, R. 2014. "Context-aware adaptive and personalized mobile learning delivery supported by UoLmP," Journal of King Saud University-Computer and Information Sciences (26:1), pp. 47-61.

Gupta, S., and Bostrom, R. 2013a. "An Investigation of the Appropriation of Technology-Mediated Training Methods Incorporating Enactive and Collaborative Learning," Information Systems Research (24:2), pp. 454-469.

Gupta, S., and Bostrom, R. 2013b. "Research Note-An Investigation of the Appropriation of TechnologyMediated Training Methods Incorporating Enactive and Collaborative Learning," Information Systems Research (24:2), pp. 454-469.

Hamari, J. 2013. "Transforming homo economicus into homo ludens: A field experiment on gamification in a utilitarian peer-to-peer trading service," Electronic Commerce Research and Applications (12), pp. $236-245$.

Hamari, J., Koivisto, J., and Sarsa, H. 2014. "Does Gamification Work? - A Literature Review of Empirical Studies on Gamification," Hawaii International Conference on System Science.

Hanus, M. D., and Fox, J. 2015. "Assessing the effects of gamification in the classroom: A longitudinal study on intrinsic motivation, social comparison, satisfaction, effort and, academic performance," Computers \& Education (80), pp. 152-161.

Hevner, A. R., March, S. T., Park, J., and Ram, S. 2004. "Design Science in Information System Research," MIS Quarterly (28:1), pp. 75-105.

Huang, Y.-M., Jeng, Y.-L., and Huang, T.-C. 2009. "An educational mobile blogging system for supporting collaborative learning," Educational Technology \& Society (12:2), pp. 163-175.

Hunicke, R., LeBlanc, M., and Zubek, R. 2004. "MDA: A formal approach to game design and game research," (4:1).

Janson, A., Ernst, S.-J., and Söllner, M. 2016. "How Cultural Values Influence the Appropriation of Technology-Mediated Learning".

Janson, A., Peters, C., and Leimeister, J. M. 2014a. "Der Weg zur effizienten Bereitstellung kultursensitiver Dienstleistungen-erste Schritte mittels systematischer Modularisierung," in Dienstleistungsmodellierung 2014: Springer, pp. 266-286.

Janson, A., Peters, C., and Leimeister, J. M. 2017a. "The Efficient Provision of Culture-Sensitive Services: A Modularization Approach," in Serviceology for Smart Service System: Springer, pp. 147-157.

Janson, A., Söllner, M., Bitzer, P., and Leimeister, J. M. 2014b. "Examining the effect of different measurements of learning success in technology-mediated learning research".

Janson, A., Söllner, M., and Leimeister, J. M. 2017b. "Individual Appropriation of Learning Management Systems: Antecedents and Consequences," AIS Transactions on Human-Computer Interaction (9:3).

Janson, A., and Thiel de Gafenco, M. (eds.). 2015. Engaging the Appropriation of Technology-Mediated Learning Services-A Theory-Driven Design Approach, Association for Information Systems.

Joosten, T., and Stoerger, S. 2011. "Curricular Redesign Grant Proposal 2011-2012 Project Title: Exploring Mobile Technologies to Increase Student Learning".

Jurado, J. L., Collazos, C. A., and Paredez, L. M. 2014. "Collaborative framework for the management of knowledge, an approach from gamification techniques," Interaccion.

Kim, Y. H., Kim, D. J., and Wachter, K. 2013. "A study of mobile user engagement (MoEN): Engagement motivations, perceived value, satisfaction, and continued engagement intention," Decision Support Systems (56), pp. 361-370.

Koole, M. L. 2009. "A model for framing mobile learning," Mobile learning: Transforming the delivery of education and training (1:2), pp. 25-47.

Law, F. L., Zarinah, M. K., and Chun, K. G. 2011. "Gamification towards sustainable mobile application," Malaysian Conference in Software Engineering.

McAuley, E., Duncan, T., and Tammen, V. V. 1989. "Psychometric properties of the Intrinsic Motivation Inventory in a competitive sport setting: A confirmatory factor analysis," Research quarterly for exercise and sport (60:1), pp. 48-58.

Melero, J., Hernándes-Leo, D., and Manatunga, K. 2015. "Group-based mobile learning: Do group size and sharing mobile devices matter?” Computers in Human Behavior (44), pp. 377-385.

Mummendey, H. D. 1990. Psychologie der Selbstdarstellung, Göttingen.

Palomo-Duarte, M., Dodero, M. J., and García-Domínguez, A. 2014. "Betting system for formative code review in educational competitions," Expert Systems with Applications (41:5), pp. 2222-2230. 
Peffers, K., Tuunanen, T., Rothenberger, M. A., and Chatterjee, S. 2007. "A design science research methodology for information systems research," Journal of Management Information Systems (24:3), pp. 45-77.

Perry, B. 2015. "Gamifying French Language Learning: a case study examining a quest-based, augmented reality mobile learning-tool," Procedia Computer Science (174), pp. 2308-2315.

Pieri, M., and Diamantini, D. 2009. "From e-learning to mobile learning: New opportunities," Mobile Learning, p. 183.

Pintrich, P. R. 1991. "A manual for the Motivated Strategies for Learning Questionair (MSLQ)".

Ryan, R. M., and Deci, E. L. 200o. "Self-determination theory and the facilitation of intrinsic motivation, social development, and well-being," American Psychologist (55:1), pp. 68-78.

Ryan, R. M., Rigby, S. C., and Przybylski, A. 2006. "The Motivational Pull of Video Games: A SelfDetermination Theory Approach," Motiv Emot (30), pp. 347-363.

Schlagenhaufer, C., and Amberg, M. 2015. "A Descriptive Literature Review and Classification Framework for Gamification in Information Systems," European Conference on Information Systems (ECIS).

Seo, Y., Kim, M., Jung, Y., and Lee, D. 2017. "Avatar face recognition and self-presence," Computers in Human Behavior (69), pp. 120-127.

Sharples, M., Corlett, D., and Westmancott, O. 2002. "The design and implementation of a mobile learning resource," Personal and Ubiquitous computing (6:3), pp. 220-234.

Söllner, M., Bitzer, P., Janson, A., and Leimeister, J. M. 2017. "Process is king: Evaluating the performance of technology-mediated learning in vocational software training," Journal of Information Technology, pp. 1-21.

Su, C.-H., and Cheng, C.-H. 2013. "A mobile game-based insect learning system for improving the learning achievements," Procedia-Social and Behavioral Sciences (103), pp. 42-50.

Thiebes, S., Lins, S., and Basten, D. 2014. "Gamifying Information Systems: A Synthesis of Gamification Mechanics and Dynamics," European Conference on Information Systems.

Tinsley, H. E., and Weiss, D. J. 1975. "Interrater reliability and agreement of subjective judgments," Journal of Counseling Psychology (22:4), p. 358.

Vom Brocke, J., Simons, A., Riemer, K., Niehaves, B., Plattfaut, R., and Cleven, A. 2015. "Standing on the Shoulders of Giants: Challenges and Recommendations of Literature Search in Information Systems Research.," Communications of the Association for Information Systems (37:9), pp. 205-244.

Vos, N., van der Meijden, H., and Denessen, E. 2011. "Effects of constructing versus playing an educational game on student motivation and deep learning strategy use," Computers \& Education (56:1), pp. 127137.

Walker, K. 2006. "Introduction: Mapping the Landscape of Mobile Learning," in Big Issues in Mobile Learning, M. Sharples (ed.), pp. 3-4.

Webster, J., and Watson, R. T. 2002. "Analyzing the Past to Prepare for the Future: Writing a Literature Review," MIS Quarterly (26:2), pp. 13-23.

Zichermann, G., and Cunningham, C. 2011. Gamification by design: Implementing game mechanics in web and mobile apps: O'Reilly Media, Incorporation. 